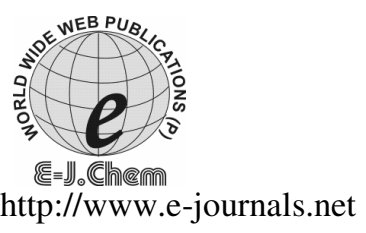

\title{
Synthesis, Spectral Characterization and Evaluation of Pharmacodynamic Activity of Copper and Nickel Complexes of Ethambutol Dihydrochloride
}

\author{
M. MATHRUSRI ANNAPURNA*, \\ M.E. BHANOJI RAO and B.V.V. RAVI KUMAR \\ Department of Pharmaceutical Chemistry \\ Roland Institute of Pharmaceutical Sciences \\ Ambapua, Berhampur, Orissa-760010 \\ E mail: mathrusri2000@yahoo.com
}

Received 8 July 2006; Accepted 22 August 2006

\begin{abstract}
Nickel and copper complexes of ethambutol [EB] were synthesized and characterized. On the basis of spectral and thermal data an octahedral geometry was assigned to the complexes with molecular formulae $\left[\mathrm{Cu}\left(\mathrm{C}_{10} \mathrm{H}_{24} \mathrm{~N}_{2} \mathrm{O}_{2}\right)_{2} \mathrm{Cl}_{2}\right]$ $5 \mathrm{H}_{2} \mathrm{O}$ and $\left[\mathrm{Ni}\left(\mathrm{C}_{10} \mathrm{H}_{24} \mathrm{~N}_{2} \mathrm{O}_{2}\right)_{2} \mathrm{Cl}_{2}\right] 2 \mathrm{H}_{2} \mathrm{O}$. Coordination of ethylene diamine derivative to the metal ion was proposed. The anti-tubercular activity of the complexes was evaluated using Lowenstein-Jensen medium and MABA [Microplate Alamar Blue Assay] methods.
\end{abstract}

Keywords: Ethambutol, ligand, metal complex, anti-tubercular activity, MABA.

\section{Introduction}

Literature survey indicates that over the last decade there has been tremendous attention towards studies on metal complex formation using drugs as ligands. The main motive of this work is to lower the side effects while maintaining similar or higher efficacy than the parent organic drug. The present investigation aims the study of $\mathrm{Ni}[\mathrm{II}]$ and $\mathrm{Cu}[\mathrm{II}]$ complexes with ethambutol dihydrochloride, which is chemically known as 2, 2' -ethylene diamine-di butanol dihydrochloride [Figure 1]. It is an anti-tubercular $\operatorname{drug}^{1}$ with molecular formula $\mathrm{C}_{10} \mathrm{H}_{24} \mathrm{~N}_{2} \mathrm{O}_{2}$. Complexation of ethambutol was largely limited to copper ${ }^{2-5}$ with isolated reports on other metals like zinc and platinum ${ }^{6,7}$. The present study explains the copper and nickel complex formation and their biological activity. 
<smiles>CCC(CO)NCCNC(CC)CO</smiles>

Figure 1. Structure of Ethambutol dihydrochloride

\section{Experimental}

\section{Instruments}

The elemental analysis of carbon, hydrogen and nitrogen was carried out using a Thermo finnigan, FLASH EA 1112 series model. Infrared spectra were recorded on a Perkin Elmer model No. 221 instrument operating within the range 400 to $4000 \mathrm{~cm}^{-1}$ using $\mathrm{KBr}$ disc technique. Thermal analysis was carried out between $30^{\circ} \mathrm{C}-700^{\circ} \mathrm{C}$ at the rate of $10^{\circ} \mathrm{C} / \mathrm{min}$ in air using SHIMADZU model.

\section{Reagents}

All the chemicals used were of analytical grade. The ligand EB was obtained from Themis Chemicals, Mumbai [India] and was used as such.

\section{Synthesis of Complexes}

Weighed amount of copper chloride [Merck] or nickel chloride [Merck] was added to calculated amount of the ligand, ethambutol in 1: 2 molar ratio using methanol as the reaction medium. The mixture was refluxed on a water bath for about 2 hours and kept at room temperature resulting in the formation of crystalline compounds. The copper and nickel complexes so formed were washed, recrystallized and dried over phosphorous pentoxide.

\section{Evaluation of pharmacodynamic activity [Anti-Tubercular Activity]}

In vitro testing of the metal complexes for the anti-tubercular activity was carried out by two methods. Method A was adopted by M. L. Dhar et $\mathrm{al}^{8}$ using Lowenstein-Jensen medium? Method B was Microplate Alamar Blue Assay (MABA) ${ }^{10}$.

\section{Method A}

M. tuberculosis var. hominis $\mathrm{H}_{37} \mathrm{Rv}$ strain was maintained on I.U.T.[International Union against Tuberculosis medium]. M. Tuberculosis was grown on Lowenstein-Jensen medium. The anti-tubercular activity of the two complexes were found out by determining their 'minimum inhibitory concentrations' (M.I.C.)

\section{Method B}

The MABA assay was carried out on High Throughput Screening (HTS) machine using Mycobacterium tuberculosis strains. The susceptibility testing with Alamar blue was performed in 96 -well flat bottom plates as described by Franzblau et al ${ }^{11}$, with some modifications. The standard anti-tubercular drugs Rifamycin, Isoniazid, Ethambutol and Streptomycin (MIC range 3- $0.3 \mu \mathrm{g} / \mathrm{ml}$ ) were taken as positive controls. The inoculum for MABA was prepared by diluting log phase growth cultures with sterile Middlebrook $7 \mathrm{H} 9$ broth supplemented with $0.2 \%$ glycerol and $10 \%$ OADC enrichment (oleic acid, albumin, dextrose and catalase) without Tween 80 (7H9-T). The two complexes, copper(II)-ethambutol (EB-Cu) and nickel(II)-ethambutol (EB-Ni) were tested at a concentration of $25 \mu \mathrm{g} / \mathrm{ml}$. 


\section{Results and Discussion}

On the basis of elemental analysis the structural formulae of the complexes were $\left[\mathrm{Cu}\left(\mathrm{C}_{10}\right.\right.$ $\left.\mathrm{H}_{24} \mathrm{~N}_{2} \mathrm{O}_{2}\right)_{2} \mathrm{Cl}_{2}$ ] $5 \mathrm{H}_{2} \mathrm{O}$, [Ni $\left.\left(\mathrm{C}_{10} \mathrm{H}_{24} \mathrm{~N}_{2} \mathrm{O}_{2}\right)_{2} \mathrm{Cl}_{2}\right] 2 \mathrm{H}_{2} \mathrm{O}$. The copper complex (violet) was soluble in water, acetone, dimethyl formamide and insoluble in chloroform. The nickel complex (green) was found to be highly soluble in both water and methanol. Their physical and analytical data are given in Table 1 .

Table 1. Physical properties and analytical data of metal complexes of Ethambutol

\begin{tabular}{|c|c|c|c|c|c|}
\hline \multirow{2}{*}{ Compound } & \multirow{2}{*}{ Colour } & \multirow{2}{*}{$\begin{array}{l}\text { M.P. } \\
{ }^{\circ} \mathrm{C}\end{array}$} & \multicolumn{3}{|c|}{$\%$ Analysis Found (Calc.) } \\
\hline & & & $\mathrm{C}$ & $\mathrm{H}$ & $\mathrm{N}$ \\
\hline $\begin{array}{c}{\left[\mathrm{Cu}\left(\mathrm{C}_{10} \mathrm{H}_{24} \mathrm{~N}_{2} \mathrm{O}_{2}\right)_{2}\right.} \\
\left.\mathrm{Cl}_{2}\right] 5 \mathrm{H}_{2} \mathrm{O}\end{array}$ & Violet & 110 & $\begin{array}{l}37.85 \\
(37.94)\end{array}$ & $\begin{array}{c}9.24 \\
(9.17)\end{array}$ & $\begin{array}{l}8.93 \\
(8.85)\end{array}$ \\
\hline $\begin{array}{c}{\left[\mathrm{Ni}\left(\mathrm{C}_{10} \mathrm{H}_{24} \mathrm{~N}_{2} \mathrm{O}_{2}\right)_{2}\right.} \\
\left.\mathrm{Cl}_{2}\right] 2 \mathrm{H}_{2} \mathrm{O}\end{array}$ & Green & 128 & $\begin{array}{l}41.75 \\
(41.83)\end{array}$ & $\begin{array}{l}9.10 \\
(9.06)\end{array}$ & $\begin{array}{l}9.85 \\
(9.76)\end{array}$ \\
\hline
\end{tabular}

\section{IR Studies}

The broad peak between $3450-3200 \mathrm{~cm}^{-1}$ and the sharp peak at $1055 \mathrm{~cm}^{-1}$ in the IR spectrum of the ligand, EB were retained in both copper and nickel complexes confirming that the primary alcohol group present in EB does not participate in complex formation. The band at $1620 \mathrm{~cm}^{-1}$ due to N-H bending in EB was shifted to $1555 \mathrm{~cm}^{-1}$ and $1560.1 \mathrm{~cm}^{-1}$ in copper and nickel complexes respectively. The shifting of the bands towards lower wave numbers indicates the complex formation ${ }^{12}$. The strong band around at $3000 \mathrm{~cm}^{-1}$ indicates the presence of coordinated water molecules.

\section{Thermal Studies}

The TGA and DTA curve for the EB-Copper complex [EB-Ni] exhibited a three-stage decomposition pattern. The first stage at about $90^{\circ} \mathrm{C}$ attributed to the liberation of one crystalline water molecule while the second at about $240^{\circ} \mathrm{C}$ is due to liberation of coordinated water molecules. According to Nikolaev ${ }^{13}$ et al. water eliminated above $150^{\circ} \mathrm{C}$ can be considered as coordinated water. Two endothermal peaks in DTA showed these steps. The inflexion points of the endotherms were located at $110^{\circ} \mathrm{C}$ and at $180^{\circ} \mathrm{C}$. Above $325^{\circ} \mathrm{C}$ there was complete decomposition of the complex and the mass loss consideration confirmed the products to be corresponding metal oxides $(\mathrm{CuO})$. In case of ethambutolnickel complex [EB-Cu] the decomposition started at $40^{\circ} \mathrm{C}$. In the first stage, the complex decomposes between $140^{\circ} \mathrm{C}-220^{\circ} \mathrm{C}$ with a weight loss of $5.01 \%$ (Calc. $5.12 \%$ ) indicating the complete removal of coordinated water molecules ${ }^{13}$. In the second stage it shows a weight loss of $58.37 \%$ (Calc. $58.0 \%$ ) between $250^{\circ} \mathrm{C}-390^{\circ} \mathrm{C}$ due to the decomposition of the ligand molecule. Finally, at $420^{\circ} \mathrm{C}-550^{\circ} \mathrm{C}$ the TGA curve represents the complete oxidation of the remaining organic molecule with the formation of a stable metal oxide $(\mathrm{NiO})$ as the final product with a weight loss of $16.67 \%$ (Calc. 16.69\%).

\section{Conclusion}

Basing on the above, it can be concluded that both the copper and nickel complexes have octahedral geometry and they are of $\mathrm{ML}_{2}$ type. The plausible structure of the complex was 
given in Figure 2. Regarding the biological activity, the two complexes were proved to be active with M.I.C. of $25 \mu \mathrm{g} / \mathrm{ml}$ using Method A. In Method B using MABA the compounds are usually considered to be active only if they show percentage inhibition $\geq 90 \%$ as compared with control. The ethambutol-copper complex showed $97 \%$ inhibition activity and the ethambutol-nickel complex showed $93 \%$ inhibition activity at concentration $25 \mu \mathrm{g} / \mathrm{ml}$. The present results confirmed that the metal complexes have great potential as anti-tubercular agents.

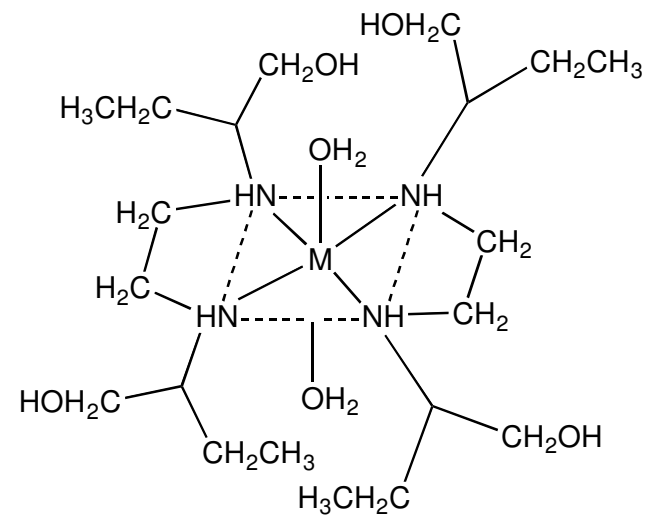

Figure 2. Structure of the metal complex of Ethambutol $\mathrm{M}=\mathrm{Cu}[\mathrm{II}]$ or $\mathrm{Ni}[\mathrm{II}]$

\section{Acknowledgement}

The authors are thankful to M/S Roland Institute of Pharmaceutical sciences, Berhampur, Orissa for providing research facilities and Themis Chemicals, Mumbai for supplying ethambutol.

\section{References}

1. Lee C S and Benet L Z, Anal. Profiles. Drug. Subs, 1978, 7, 231.

2. $\quad$ Cole A, May P M and Williams D R, Agents Actions, 1981, 11, 296.

3. Gupta V K, Prasad R and Azad Kumar, Talanta, 2003, 60, 149.

4. Bemski G, Rieber M and Reyes H, FEBS Lett, 1972, 23, 59.

5. Felder E, Pitre D and Grandi M, Farmaco [Sci], 1970, 25, 618.

6. Weismann K, Dan Med Bull, 1986, 33, 208.

7. Benedetti M, Malina J, Kasparkova J, Brabec V and Natile G Environmental Health Perspectives, 2002, 110779.

8. Dhar M L, Dhar M M, Dhavan B N, Mehrotra B N and Ray C, Indian J. Exp. Biol, 1968, 6, 232.

9. Srivastava A, Ph. D. Thesis, Kanpur University, India, 1982.

10. Collins L A and Franzblau S G, Antimicrob. Agents Chemother. 1997, 41, 1004.

11. Franzblau S G, Witzig R S, McLaughlin J C, Torres P, Madico G, Hernandez A, Degnan M T, Cook M B, Quenzer V K, Ferguson R M and Gilman R H, J. Clin. Microbiol., 1998, 36, 362 .

12. Nakamoto K, Infrared Spectra and Coordination Compounds; Wiley Interscience: New York, 1986.

13. Nikolaev A V, Longvinenko V A and Mychina C I, Thermal Analysis, Academic Press, New York, 1969. 


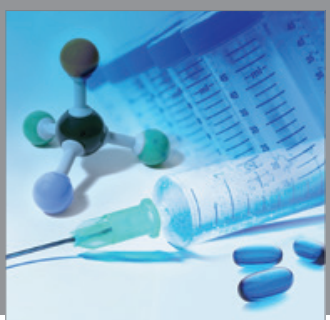

International Journal of

Medicinal Chemistry

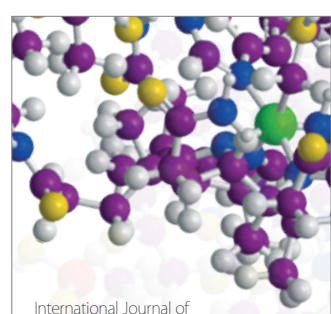

Carbohydrate Chemistry

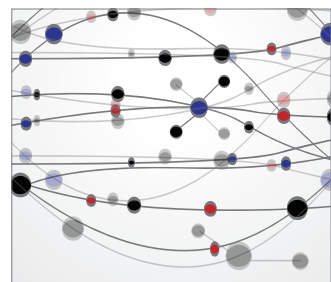

The Scientific World Journal
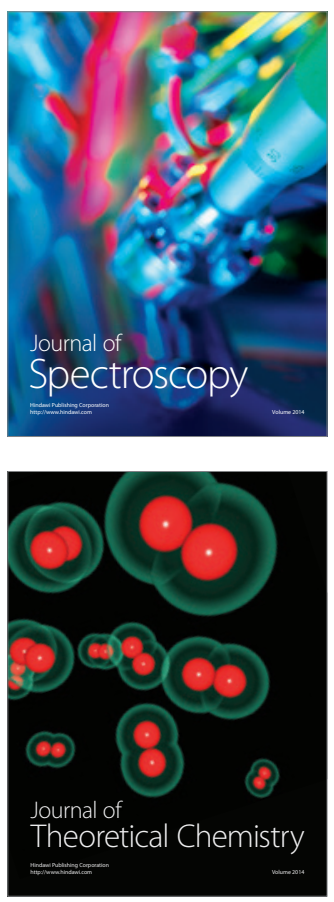
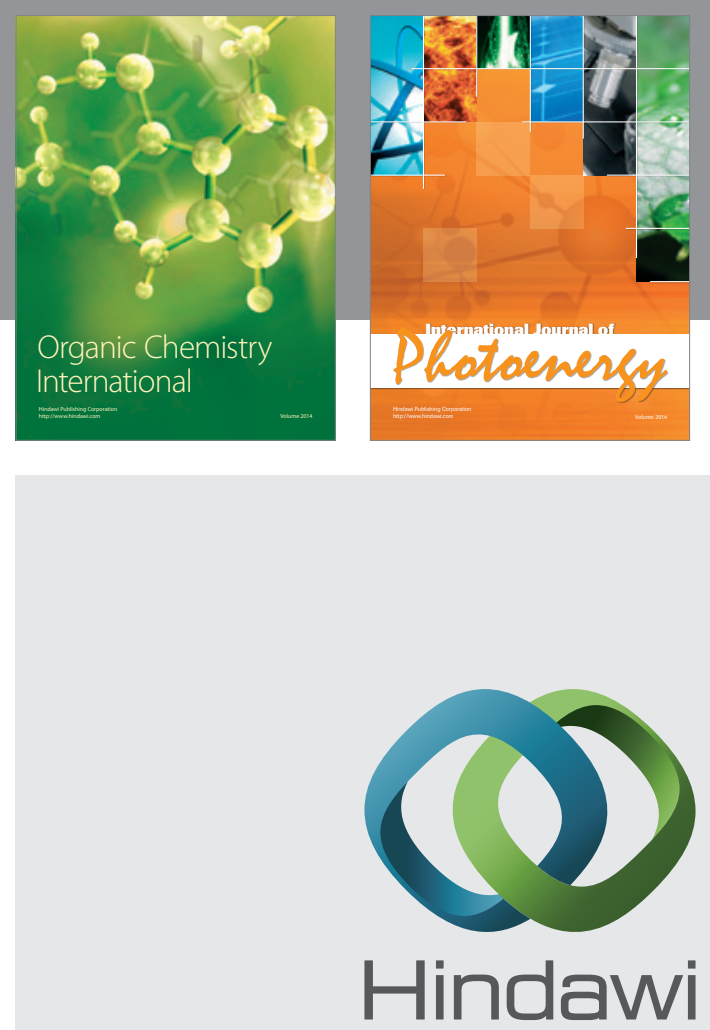

Submit your manuscripts at

http://www.hindawi.com
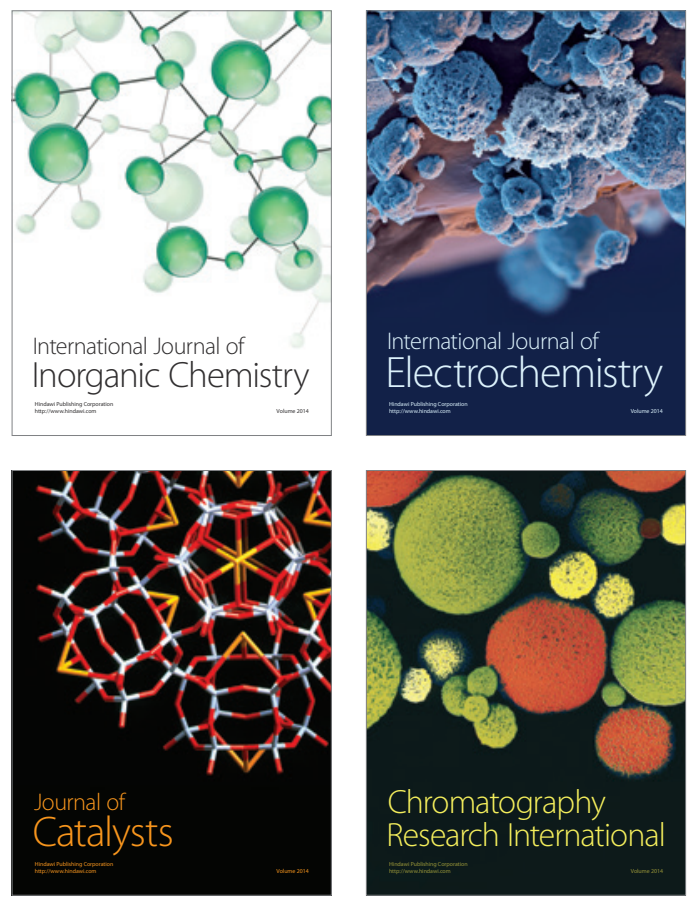
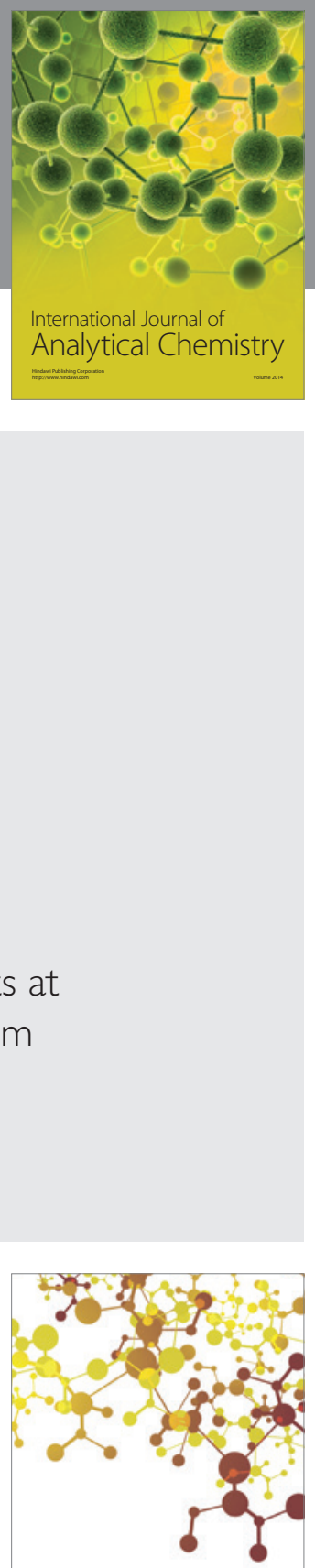

Journal of

Applied Chemistry
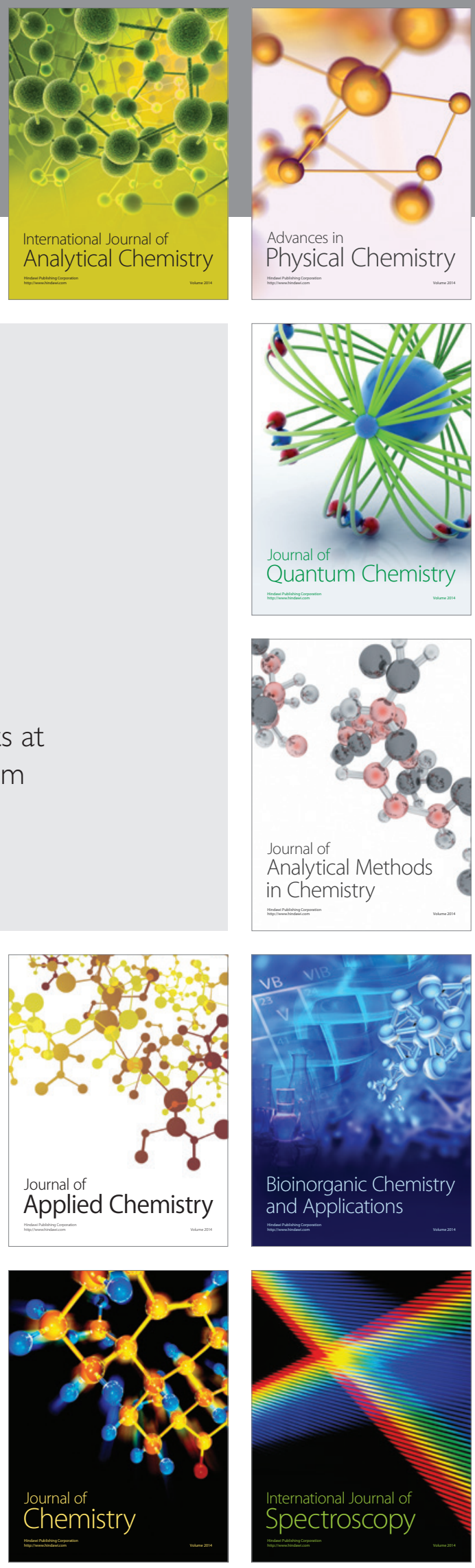